\title{
Capítulo 10 VISIÓN DEL CAMBIO SOCIAL DESDE LAS FARC
}

El marco de análisis del discurso de las FARC, para los propósitos de esta tesis, está referido a aquel que, presentado de forma sistemática en el discurso, pero también como texto, denominado Los problemas estratégicos y tácticos de la revolución en Colombia (tesis de discusión sometidas al Comité Ejecutivo del Partido Comunista de Colombia) (Indal, 1972), en 1967 da cuenta de una época y de los debates que siguieron vigentes durante mucho tiempo, tanto en las filas de las guerrillas como en la intelectualidad y movimientos sociales que intentaban dar respuesta a los problemas sociales presentes en la sociedad colombiana, como punto de referencia. Estas intenciones estuvieron también presentes con las variaciones contextuales esperadas en otras latitudes del continente americano. De allí la selección de este texto.

Es resaltable que este texto se constituye en referente del discurso de la insurgencia en Latinoamérica, no solo por el hecho de expresar con claridad conceptual e integral lo que en otros contextos se encuentra parcialmente en textos de otros grupos insurgentes o por aparecer en su versión ideológica para movilizar a las poblaciones, sino porque en la medida en que las FARC mantenían contacto directo con la intelectualidad insurgente de las guerrillas latinoamericanas, a su vez cristalizaban planteamientos que se vienen dando con matices en otros países.

Se encontró en el análisis del texto que tres puntos permiten mostrar la posición de las FARC frente a la problemática del cambio social en los años sesenta y setenta, que además proponen una postura frente a la realidad que implicó desarrollos de la sociedad colombiana que hoy en día siguen su desenvolvimiento 
en aras de consolidar desarrollo, paz y cambios en el sistema, los cuales, a su vez, permitan el mejoramiento de la calidad de vida del pueblo colombiano. Ellos son: la situación revolucionaria, como diagnóstico; la vía revolucionaria, como explicación de los caminos que la coyuntura ofrece para el cambio social; y los problemas por resolver, como prospectiva del proceso y ejes articuladores con otros actores de la sociedad.

\section{LA SITUACIÓN REVOLUCIONARIA}

Detrás de la postura de la guerrilla estaban los debates con partidos de izquierda, entre ellos, si era pertinente o no acudir a la vía revolucionaria para resolver los problemas de injusticia social de la sociedad colombiana. Ya para la época, el referente del éxito de la Revolución cubana parecía resolver la pregunta; sin embargo, la arremetida de los gobiernos americanos, incluido (muchas veces propiciado por) Estados Unidos, para disolver cualquier intento de réplica en el continente llevaba nuevamente a esta pregunta al campo conceptual y de análisis histórico-contextual que diera luces sobre el camino por seguir.

Muchos autores han referido la incapacidad de la izquierda de separarse de la doctrina marxista para abordar su propio contexto, en especial para dar cuenta diferenciada de la experiencia europea del proceso de cambio social al que Latinoamérica se veía abocada. Es cierto que la utopía socialista había llenado los corazones de los pueblos latinoamericanos, convirtiéndola en vector de la acción social en muchas dimensiones; sin embargo, cómo alcanzar la meta era una incógnita difícil de resolver.

La pregunta principal estaba, entonces, alrededor de si existía o no una situación revolucionaria que diera lugar, casi que de forma automática, al levantamiento del pueblo, para iniciar el proceso de cambio estructural necesario para resolver los problemas de pobreza, inequidad e injusticia social presentes en los distintos países de Latinoamérica. En el texto de referencia se resaltan seis aspectos presentados en la siguiente ilustración (figura 5). 
Figura 5. Condiciones que dan lugar a la situación revolucionaria

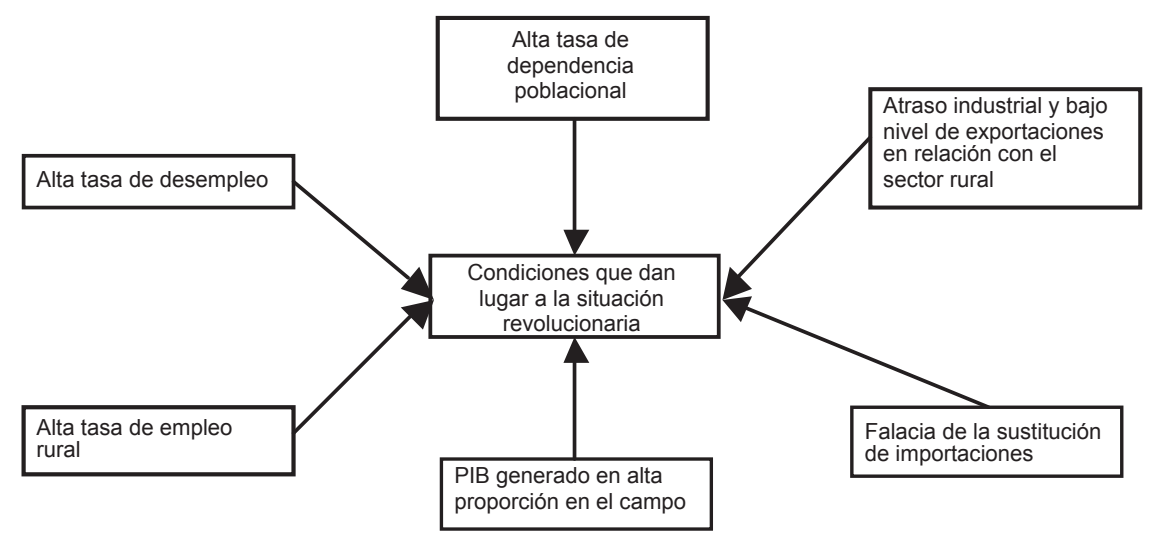

Fuente: autor, a partir de FARC (1967).

Como se puede ver, con ellos se intentaba hacer un pequeño diagnóstico de puntos clave desde el punto de vista socioeconómico que identificaban factores que pudieran ser detonantes de un cambio por la vía revolucionaria del sistema existente. Es claro que su análisis no se reducía a estos aspectos, pero sí desde ellos se podía definir quiénes serían los posibles agentes del cambio social, pues podrían ser los principales afectados de la situación.

Frente a los planteamientos clásicos de que el obrero capitalista era el llamado a ser el agente de dicho cambio, como se planteaba en el Manifiesto del Partido Comunista, en alianza con el campesinado, en el caso de este Congreso el marco se ampliaba al siguiente escenario de actores sociales llamados a aliarse frente a la situación existente:

1. trabajadores

2. obreros asalariados

3. campesinos asalariados

4. campesinos aparceros

5. artesanos urbanos y rurales

6. asalariados de la producción de servicios 


\section{7. pequeños comerciantes}

8. pequeños y medianos propietarios agrícolas

9. pequeños y medianos industriales

10.industriales no ligados al imperialismo

Como se puede ver, se consideraba que la situación de injusticia afectaba a amplias capas de la sociedad, por lo cual lograr el cambio por la vía revolucionaria era solo cuestión de tiempo, pero requería su "empujoncito". Así como en el ámbito nacional se veía la necesidad de unificar las fuerzas, siempre se mantuvo vigente la visión de que esto debía replicarse a nivel internacional, porque la sostenibilidad de cualquier cambio radical como este requería del concurso y apoyo de otros pueblos, además de la expansión de los logros a los vecinos como parte de ese deber revolucionario.

En términos analíticos es importante resaltar que esta enumeración inicial de agentes de cambio daba una imagen clara, a los receptores del discurso, de quiénes eran aquellos a los que hacía alusión el discurso cuando se refería al pueblo. Esta categoría continuamente expresada en el debate filosófico, especialmente en el marco de la filosofía política, aquí buscaba ser expresada con referentes tangibles con dos propósitos evidentes: determinar a quiénes estaba directamente dirigido el discurso y diluir resquemores existentes frente al discurso revolucionario, en el que muchos temían perder sus escasos logros económicos a la hora de asumir un modelo de economía socialista. La misión era, definitivamente, unificar fuerzas en torno a un propósito común que permitiera acceder a beneficios sociales superiores a los que ofrecía el sistema vigente y que claramente debían beneficiar a ese "pueblo".

Para el caso de estos cuadros directivos de las FARC, y en el contexto de la época a la que nos referimos, dicha revolución debía darse como una "revolución agraria antiimperialista”, es decir, como medio para lograr la liberación nacional. De allí que el referente con el que se le ha caracterizado y criticado sea el de ser una guerrilla campesina con una visión de ese tenor; sin embargo, algunos de los planteamientos muestran una visión que va más allá, pero que a la vez no puede distanciarse de quienes integran los grupos guerrilleros como origen y referentes del mundo de la vida.

Finalmente, hay que poner de presente en esta contextualización de la situación revolucionaria un aspecto que aparece como determinante en la visión de 
este discurso, que a la vez ofrece sentido de realidad y posibilidad al conjunto de factores analizados: el de la guerra fría. Como es costumbre tanto en las ciencias como en la realidad, este elemento del contexto facilitaba el análisis polar de las alternativas, dado que las situaba políticamente; sin embargo, es resaltable que aquí se busca una salida particular de la realidad social latinoamericana, como se ve en los planteamientos de Antonio García referidos en este trabajo investigativo, en el que se procuraba construir un modelo de democracia acorde con las condiciones de desarrollo específico de nuestras naciones y los principios rectores que debían transformar el modelo de sociedad.

\section{LA VÍA REVOLUCIONARIA}

Toda esta cuestión de la situación revolucionaria también permitió hacer precisiones sobre la vía para lograr ese cambio social, pero que a la vez hace posible proyectar hoy la dificultad de lograr una paz negociada, como mirada de la disolución del conflicto más que de su resolución.

En el marco de estas tesis sometidas por las FARC al Comité Ejecutivo del Partido Comunista, los conceptos de violencia dieron pie a caracterizar el papel revolucionario y legitimador de la lucha armada. En el marco de esa situación revolucionaria, la violencia reaccionaria y la violencia represiva de las élites en el poder, dicen, eran de esperarse, por las acciones que ellos venían realizando. En ese sentido, la persecución a líderes populares y dirigentes del partido comunista consideraban que debían haber sido previstas desde un marco más amplio de la acción revolucionaria. Aunque las acciones del gobierno le implicara la deslegitimación de su actuar, la pregunta puesta por las FARC al Partido Comunista estuvo en relación con la necesidad de un partido político al lado y director del brazo armado. Era interesante para ese momento la relevancia que se le daba a la subordinación de la acción armada a la acción política.

Hoy en día este planteamiento de la subordinación de la acción armada a la acción política se concluye como uno de los grandes aportes de la época a los nuevos movimientos y a la lógica de la resolución de los conflictos en el mundo. Basta mirar los discursos del comandante Marcos y el impacto que el EZLN ha tenido en el mundo, en parte por esta postura. Quienes analizan la actuación de los grupos guerrilleros en Latinoamérica permanentemente evidencian la existencia de esta postura como la que define la vigencia política de los grupos guerrilleros, 
mientras que sus detractores acusan su descomposición en la medida que no es evidente la acción política de los grupos guerrilleros y su aporte en términos de las ideas a los problemas de la sociedad. Para el análisis de los conflictos, allí se encuentra la verdadera posibilidad de cambio social, pues el escenario de lo político, como escenario de la toma de decisiones de los grupos sociales, es el llamado a desenvolver las alternativas para atender las diferencias entre los actores en un marco del ejercicio del poder.

El punto de inflexión en este discurso gira en torno a la pregunta sobre la vía revolucionaria. Los niveles de represión y la reducción del espectro de participación política vigente durante el Frente Nacional provocaba, por un lado, evidenciar la imposibilidad de una lucha pacífica de las masas para acceder a libertades y derechos considerados como necesarios dentro de la vida democrática; por otro lado, ponía en cuestión la "utopía liberal", porque se basaba en una vía reformista del "régimen" que ambos tipos de violencia demostraban inviable. Es decir, era evidente la falta de voluntad política para producir los cambios sociales necesarios; por tanto, la vía revolucionaria debía ser la conquista del poder por la fuerza, que requería no solo actuar por la vía de las armas, sino también por las vías legales.

La noción de proceso es determinante en la visión de cambio social ofrecida por el movimiento guerrillero de cara a sus interlocutores y como medio de la movilización social. Es desde allí cómo se instaura la noción de todas las formas de lucha como fundamento del cambio revolucionario. Para sorpresa de muchos hoy en día, este contexto muestra que el origen de la expresión no estaba fundamentado en las tácticas de la guerra, sino, más bien, en la definición de medios socialmente viables para producir el objetivo aglutinador de pueblo y nación, abstractamente definido como cambio social; tanto así, que en adelante se va a constituir en el referente político de campañas y propuestas de todo orden, por su vínculo intrínseco en la mente de la población con la necesidad de romper con las condiciones de vida derivadas del modelo impuesto para el gobierno político y económico de la nación.

$\mathrm{E}$ l argumento de fondo respecto a por qué no se da el cambio por la vía pacífica está referido al resultado de la "lucha pacífica de masas". La muerte de líderes, la reacción violenta de gamonales en el nivel local y, en general, la violencia represiva desde los estamentos del gobierno planteaban la necesidad de una acción de otro tipo. Se planteaba tanto una autodefensa mediante la pasividad 
armada (se había demostrado que entregar las armas era sacrificarse ante las armas del otro) como la acción guerrillera. Como se puede ver en el mapa conceptual base del presente análisis (figura 7), la acción estratégica implicaba tanto medios tácticos legales como ilegales. Por ello, la idea de liberación nacional se pueda sintetizar en el planteamiento de las FARC:

El fin del imperialismo y la marcha hacia la conquista definitiva de la libertad y el bienestar de nuestro pueblo, rompiendo las cadenas de la dependencia, se presentan como una perspectiva concreta de trabajo y de lucha (Indal, 1972, p. 118).

Como el fondo de todo el proceso es la dependencia, económica, política y social, que se revela tanto a nivel interno como internacional, el proceso debe darse en ambos ámbitos; por tanto, la búsqueda de autonomía requiere que se inicie en el pensamiento de las personas, para que así se vaya trasladando a todos los espacios de la vida social. Sin embargo, como los agentes de las fuerzas en el poder hacen resistencia, la vía armada no se descarta por parte de los grupos. Solo en la medida en que la acción armada, las más de las veces ilegal, de gamonales, terratenientes, grupos de poder y fuerzas del Estado con medios oscuros desaparezca de este escenario, la resolución del conflicto pasará totalmente al ámbito de lo político y conducirá hacia nuevos caminos tanto el proceso de paz como el proceso de cambio social.

\section{Problemas estratégicos por Resolver}

Dada la vía revolucionaria como alternativa para el cambio social, eran muchos los factores que se debían tener en cuenta a la hora de que el pueblo se tomara el poder. Y estos factores no eran puestos en el futuro, sino en la necesidad de la organización política, social y militar.

Es interesante la visión de pueblo que emerge de este texto en cuanto a escenarios para el abordaje estratégico del cambio social. Lo concibe a un mismo tiempo como clase social, como proletariado - con la enumeración ya hecha anteriormente que muestra la diversidad de actores integrantes- $y$, finalmente, como partido. Todas tres se derivan del marco de acción que debe llevar dicha vía revolucionaria. No es la toma del poder militar la que permite el cambio social ni la necesaria independencia de los factores externos; es la formación de los cuadros 
que debe asumir el gobierno del país. En ese sentido se presenta el debate de la dirección revolucionaria y la necesidad del partido como escenarios de la reflexión política, pero con un sentido práctico que facilite el alcance de frutos de forma rápida y evidente.

Por ello, las FARC le plantean al Partido Comunista las diferencias con la línea política y su aplicación práctica, en la que la autodefensa debía tener procesos de cambio que significaban una revolución dentro de la revolución y en el que, además, esa burguesía que podía ser renovadora en el fortalecimiento de la democracia podía, muy probablemente, tener que ser impulsada camino a un cambio revolucionario que por su propia voluntad no iban a ser capaces de formular, entre otras, por el temor de perder los logros que el crecimiento económico del siglo XX les había permitido. Así las cosas, se sustenta y justifica la vía armada como la necesaria para el proceso de cambio estructural. Identificar este hito para la justificación de la vía de las guerrillas es importante para el debate actual. Pero también dice mucho de la estructura esperada para ese momento, porque no se ve desligada de la construcción política del cambio. En este contexto, el reclamo que le hacen las FARC al Partido Comunista es haber afirmado la necesariedad del apoyo político a grupos como el Ejército de Liberación Nacional por concluir que la alternativa de las guerrillas era inaplazable; sin embargo, a la hora de los hechos no había cumplido con su compromiso.

En ese marco se planteó como conclusión de los resultados ofrecidos por el X Congreso del Partido Comunista:

La paz mundial no es una finalidad en sí misma y para que sus resultados sean victoriosos exige el combate a tiempo de las agresiones bélicas imperialistas y el incremento de la lucha de liberación nacional (Indal, 1972, p. 127).

Es importante recordar que este es el primer congreso después de la Revolución cubana y que de allí se deriva un fortalecimiento de la mirada de la alternativa guerrillera como opción de logro de las metas de cambio estructural. Con esta, se señalan otras tres conclusiones que muestran la apuesta que querían seguir:

1. El movimiento guerrillero es la superación de las etapas anteriores de autodefensa de masas, tiene un carácter nacional-liberador y un objetivo estratégico inmodificable: la toma del poder para el pueblo. 
2. Los objetivos revolucionarios no pueden ser alcanzados sino previa toma del poder en forma revolucionaria. Por consiguiente, no es la democracia el camino de la revolución sino la revolución el camino de la democracia. Solo la conquista revolucionaria del poder permitirá instaurar formas de gobierno que garanticen los intereses generales del pueblo y de la nación colombiana.

3. La revolución colombiana forma parte de la revolución continental iniciada con la revolución cubana (Indal, 1972, p. 127).

Por tanto, se expresa, por un lado, una visión de coyuntura que parte de considerar madura la situación revolucionaria que promovería una alternativa para la construcción de una verdadera democracia; y, por otro, una visión internacional que exige la unión de las fuerzas para acabar con la estructura de dependencia; sin embargo, es el aspecto político el más complejo de resolver. En la figura 6 se resume la visión del papel del Partido Comunista en todo este proceso, razón por la cual la guerra de guerrillas no podía ser vista como un fin en sí mismo. De esta manera, se le exige al Partido Comunista cumplir con su misión de vanguardia, pero sin suplantar la necesidad de que esta la vaya asumiendo el pueblo.

La importancia y complejidad de lo político son concebidas si se tiene claro que esta superestructura es la que le da soporte a todo el proceso de dominación y dependencia. De allí se derivan otras tantas dependencias. En el texto se muestra cómo la liberación de la industria implica "romper las estructuras sociales de explotación agraria y demoler la superestructura imperialista” (Indal, 1972, p. 122). La no existencia de clases sociales diferenciadas se plantea debido a la escasa distribución de los medios de producción; por ello, tiene un correlato ideológico que termina polarizando la sociedad y frenando su desarrollo histórico. De esta forma se va mostrando cómo la alternativa del desarrollo es una falacia que reproduce la lógica de la modernización; por ello, se le opone la del cambio social, para lo cual, y en ese momento histórico especialmente, consideran que el cambio estructural no se va a producir por las vías de la democracia burguesa por todos los antecedentes (Indal, 1972, p. 127). 
Figura 6. Papel del Partido Comunista en la propuesta de las FARC

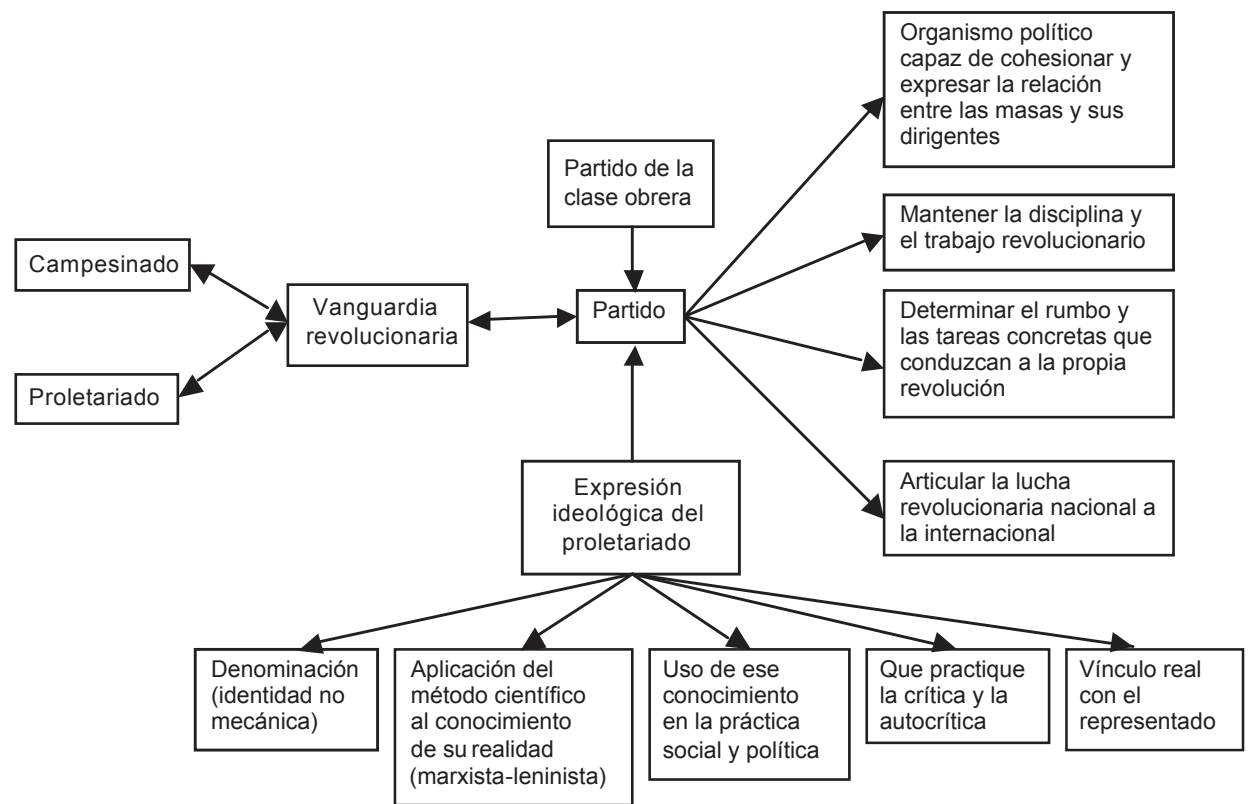

Fuente: autor, a partir de FARC (1967).

Son resaltables del esquema anterior ciertos papeles atribuidos al partido, que son claves en la mirada actual del proceso político de cara a los problemas del cambio social que se deben resolver. El primero de ellos es el papel cohesionador y de relación entre las masas y sus dirigentes. Detrás de ello se evidencia la idea de que todo proceso de cambio es un proceso social, y para ello se requiere la articulación de las acciones. Ello contrasta con la emergencia actual de partidos personalistas que se basan en la confianza en el dirigente. Para otras investigaciones sería importante analizar el impacto de este cambio en la construcción de los procesos sociales; no obstante, de forma anticipada se observa que reduce la capacidad de canalizar la diferenciación social que se expresa en la pluralidad de intereses y necesidades dentro del campo que maneja un partido con la estructura que se proponía en los años sesenta. 
Determinar el rumbo y las tareas que conduzcan a la revolución, junto con el mantenimiento de la disciplina y trabajo revolucionario, habla de un análisis profundo de la conducta social que tiende a naturalizar la imposibilidad de alcanzar logros, producida en el marco de la represión social y política; por ello, requiere de un liderazgo que mantenga el interés por el cambio, mediante propuestas permanentes de acción y trabajo, pero con una definición clara de objetivos. Esto hacía de los partidos un escenario de construcción permanente de plataformas políticas que a la larga son visiones de sociedad que dirigen la acción social. En este sentido, en el marco conceptual se evidencia la relación entre la estructuración de propuestas de discurso, que en el mediano plazo permiten observar el direccionamiento de la acción social con sentidos definidos. Así, este discurso sobre el partido es interesante rastrearlo hasta nuestros días respecto a cómo define la acción política de amplios sectores de la sociedad.

Finalmente, la diferencia entre el agente y el grupo social de referencia está precisamente en su capacidad de canalizar las ideas del grupo en diferentes entornos, y de allí el papel articulador que se le atribuye al partido como agente articulador de intereses nacionales e internacionales. De allí que esta mirada nos permita avanzar en la perspectiva latinoamericana de este actor particular de las guerrillas colombianas. La expresión particular ya nos presenta articulado en su discurso el contacto internacional que diferentes líderes tenían en la época. A diferencia de la actualidad, la movilidad internacional de los líderes guerrilleros y otros medios de contacto y debate hicieron que su discurso tuviera rasgos estratégicos comunes, por lo que no es gratuito que la mirada sobre la Revolución cubana se considerara como una amenaza para orden establecido en Latinoamérica. La revolución se exportó a varios países de Suramérica y Centroamérica, pero más como visión de bloque continental con intereses comunes, que como mera reproducción de estrategias para ganar la guerra y tomarse el poder. Por ello, su expresión se dio en lo cultural (arte y música, de forma privilegiada); en lo político, visto en el fortalecimiento de los partidos de izquierda con propuestas que volvían a calar en los grupos sociales; en el diagnóstico económico, señalando la perversidad del modelo de desarrollo imperialista o dependiente, y hasta en lo religioso, en cuanto la religiosidad debía atender las necesidades reales de los pueblos en un aquí y ahora.

En este sentido explicativo del acápite, puede verse cómo la visión de partido buscaba recoger gran parte de los problemas estratégicos por resolver, de cara 
a lograr el cambio social por la acción de múltiples vías, entre ellas la del cambio revolucionario. Desde estos principios descritos se avanza en resolver el dilema entre la línea política y la aplicación práctica; el papel que puede jugar la autodefensa en el marco de un proceso social más amplio que es capaz de articular realidades específicas de las regiones donde la violencia directa existe; incluso cómo incorporar o enfrentar la problemática del papel de la burguesía en el proceso de cambio y en la articulación de sus intereses en relación con un cambio que beneficie a la sociedad en su conjunto. Sin riqueza, sin crecimiento de la producción, es claro, no se tendrán mejores condiciones de vida, por lo cual terminan incorporándose diferentes agentes del capital en un proceso con dirección propia.

A modo de síntesis, pero también de marco de lo planteado en este capítulo, se presenta el siguiente mapa conceptual derivado del texto analizado. 
Figura 7. Mapa conceptual de la visión de la guerrilla sobre la vía del cambio social en Latinoamérica y los problemas por resolver

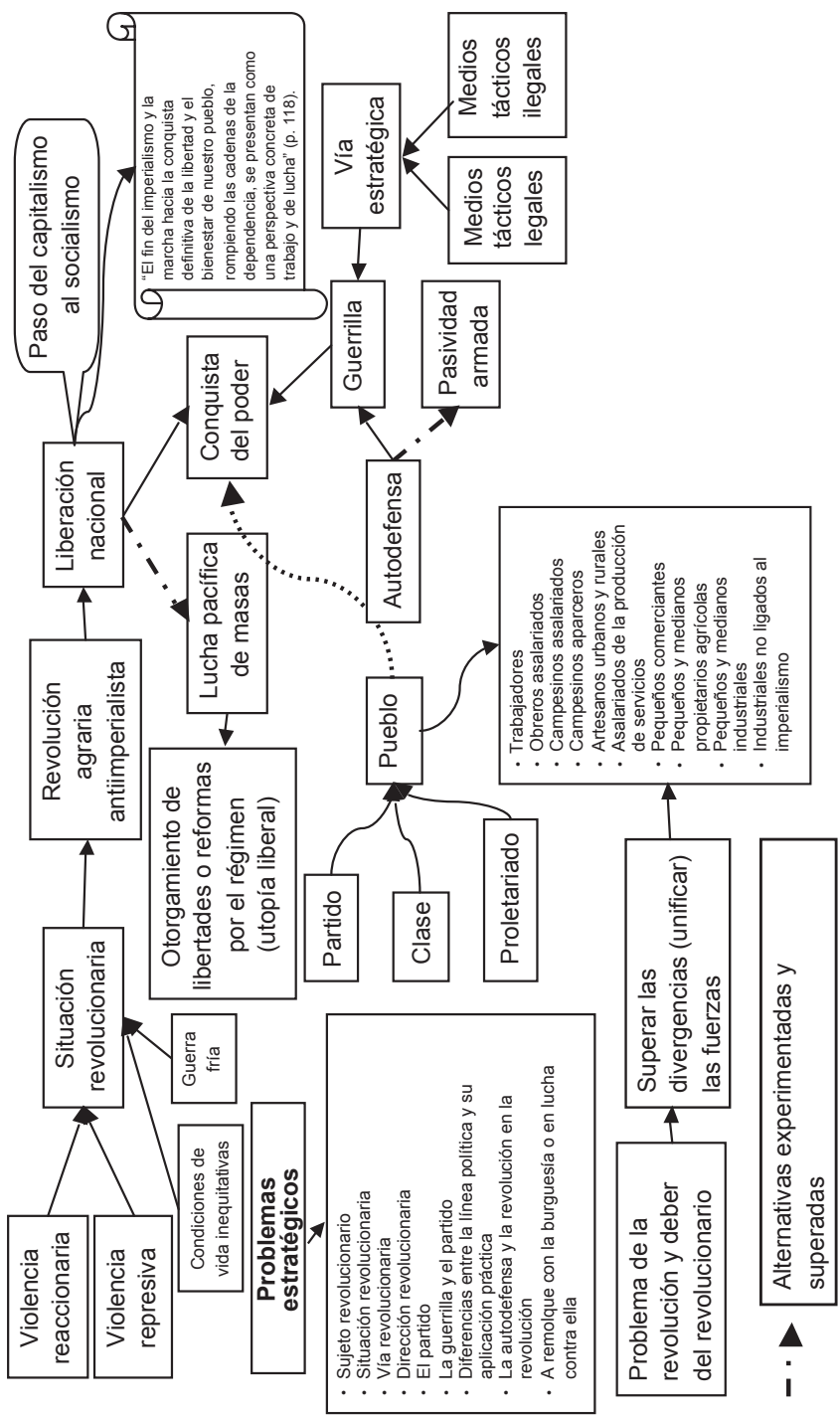

Fuente: autor, a partir del texto Los problemas estratégicos y tácticos de la revolución en Colombia (tesis de discusión sometidas al Comité Ejecutivo del Partido Comunista de Colombia en 1967). 
